\title{
Bioimpedance as a Non-Invasive Method to Evaluate Eggs and Poultry
}

http://dx.doi.org/10.1590/1806-9061-2015-0087

Review

-Author(s)
Klein DR'
Vale MM"
Silva LP'
Santos JPA'
Branco T'
Fernandes MO'

' Federal University of Santa Maria / Animal
Science Department - UFSM/DZ
" Federal University of Paraná / Animal
Science Departament - UFPR

\section{nail Address}

Corresponding author e-mail address Daniela Regina Klein

Av. Roraima, 1000, Departamento de Zootecnia-UFSM, prédio 78

97105000. Santa Maria, RS, Brazil Phone: (55) 96370532

Email: :danniwk@yahoo.com.br

\section{EKeywords}

Conductance, day-old chicks, egg storage, reactance, sexing

\section{ABSTRACT}

The need to comply with animal welfare has motivated the research for non-invasive methods that allow the evaluation of poultry and eggs to be painless while providing accurate measurements. In this scenario, bioelectrical impedance was tested as a minimally invasive tool for sexing day-old chicks of two different chicken strains and for evaluating the quality of eggs submitted to different days of storage relative to their hatchability. The resistance and phase angle measured allowed the differentiation between chicken strains, but not between sexes. Eggs stored for seven days showed higher resistance and lower phase angle those stored for only one day. Although the bioimpedance method seems to be a promising method to evaluate egg and chick quality, the results of the present study suggest that further studies are needed to validate its utilization, particularly in terms of electrode type and positioning, as well as for the determination of which electrodes and equipment are best suited for different evaluation purposes.

\section{INTRODUCTION}

The poultry production system increasingly requires non-invasive techniques which comply with ethical, and welfare requirements, and allow the development of computer systems and precise real-time measurements. Body bioimpedance is a non-invasive, safe, easy-touse, portable, and low-cost technique to estimate body composition (Lukaski 2013; Collins et al., 2013; Dittmar et al., 2015; Harrison et al., 2015), and seems to be a promising method in poultry production for the evaluation of egg and body composition.

The body intracellular and extracellularfluids behave as heterogeneous electrical conductors and cell membranes act as capacitors. However, body fat acts as an insulator, offering resistance to the current flow (Baumgartner et al., 1988). The body bioimpedance (BBI) is a simple and safe technique that allows estimating body composition, including water, electrolyte, and body fat contents using low-intensity electric current (Chumlea \& Guo, 1994; Cintra et al., 2010).

Although there are many laboratory methods to measure the egg composition factors that may influence hatchability, all are invasive, and do not allow eggs to be subsequently incubated. On the other hand, bioimpedance is a non-invasive, practical, and economical method to estimate egg composition (Yaguiyan-Colliard et al., 2015). The chemical reactions that occur inside the eggs during the storage period, which starts on the farm and ends at incubation, reduce their hatchability (Brake et al., 1997; Dymond et al., 2013, Gharib, 2013). Those reactions change egg bioimpedance (EBI), which can be measured. One example 
is albumen quality, which declines as egg storage time increases (Omana, et al., 2011).

Bioimpedance is evaluated as a function of three elements: resistance, reactance, and phase angle. Resistance (R) is a measure of the dissipation of energy in a conductive body or fluid, the reactance $(X C)$ is related to energy storage, and the phase angle (PA) is the time delay between a stimulating current and the voltage generated by an alternating current.

In humans, the applicability of bioimpedance is well established and allows to differentiate physiological conditions between sexes (Karelis et al., 2013; Collins et al., 2013). In women, these bioimpedance differences are ascribed to their relatively higher body fat content relative to men (Baumgartner et al., 1988). Therefore, we hypothesized that the sex of day-old may be differentiated using $\mathrm{BBI}$, which could reduce sexing errors. The present study was conducted to evaluate the use of bioelectrical impedance to measure the quality of hatching eggs and as a non-invasive method to sex day-old chicks.

\section{MATERIAL AND METHODS}

The experiment was conducted at the Laboratory of Poultry Science (LAVIC), Department of Animal Science, Federal University of Santa Maria, Brazil.

Bioimpedance was measured as a function of resistance $(R)$ and reactance $(X c)$, which were directly measured using a portable body composition analyzer (Quantum II, RJL Systems ${ }^{\circledR}$, USA); and phase angle (PA), calculated from the ratio between arctangent reactance and resistance (Equation 1, Baumgartner et al., 1988).

Equation 1:

$\mathrm{PA}=(\arctan X \mathrm{C} / \mathrm{R}) \times 57.296$

Where:

$\mathrm{PA}=$ phase angle;

$\arctan X \mathrm{C}=$ arc tangent of reactance $\left(\mathrm{Xc}_{\mathrm{c}}\right.$;

$\mathrm{R}=$ resistance

In Equation 1, the approximate value of 57.296 $(180 \%)$ applies to effect conversion degrees (Baumgartner et al., 1988; Chumlea \& Guo, 1994) and can vary from zero, which represents a full resistive body, to $90^{\circ}$, which corresponds to a capacitive body. The $45^{\circ}$ angle is the body with equal amount of reactance and resistance. PA is the most established bioimpedance parameter (Llames et al., 2013), and it is associated with membrane integrity and permeability, and hydration (Kyle et al., 2013).
Two experiments were conducted to verify the possibility of using bioimpedance to evaluate the quality of hatchable eggs at different days of storage, and to sex day-old chicks.

\section{EBI of hatchable eggs}

Sixty hatchable eggs, including 20 eggs laid by heavy breeders (Cobb 500 broiler breeders) and 40 eggs laid by layer breeders ( 20 from a Rhode Island Red $x$ White Plymouth Rock cross, 20 from a Rhode Island Red $x$ Barred Plymouth Rock cross) were evaluated by EBI. On the day of collection, eggs were weighed and individually identified according to strain, date, and replicate. Ten eggs per strain were stored for zero days and ten eggs were stored for seven days at room temperature (around $24^{\circ} \mathrm{C} \pm 1.5$ ).

The electrodes of the analyzer were fit in a PVC mold support to maintain the eggs in horizontal position (Figure 1). The electrodes attached to connectors were made of copper, adapted to PVC support. Two electrodes were placed on the bottom and two on top of the eggs to measure EBI.

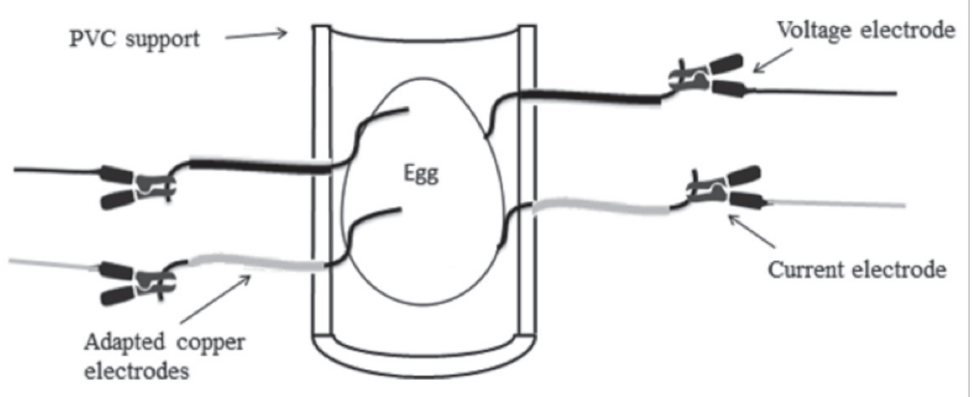

Figure1 - Position of the bioimpedance apparatus electrodes on the eggs.

EBI was measured in eggs placed in the horizontal position because of the possible interference of the PVC mold support in the case of vertical position (pole-to-pole measurement). Previous pole-to-pole measurements were rejected because of instability during measurement.

\section{BBI of day-old chicks}

Thirty-six day-old chicks, derived from the three evaluated genetic strains (Cobb 500, Rhode Island Red $x$ White Plymouth Rock cross, and Rhode Island Red $x$ Barred Plymouth Rock cross), were subjected to BBI measurements. Six females and six males of each strain were used. Broiler chicks were identified by feather sexing, and layer chicks by feather color differences.

Chicks were positioned in dorsal decubitus on a surface with insulating material and two electrodes 
were placed on each leg of each chick to measure $R$ and Xc (Figure 2).

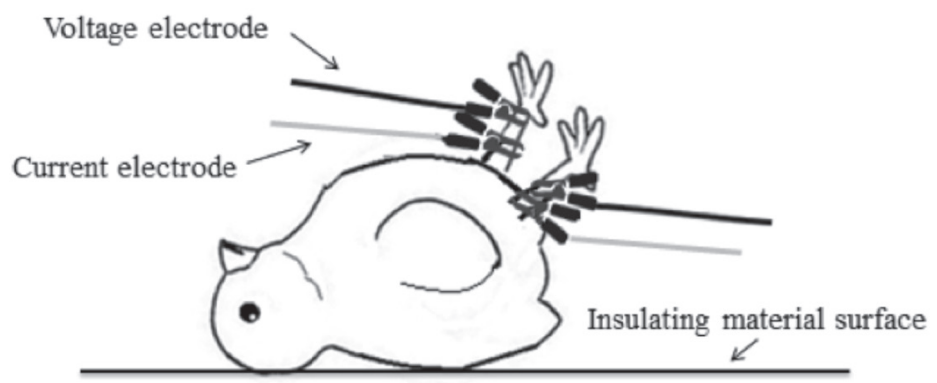

Figure 2 - Chick and electrode positions used for bioimpedance measurements.

\section{Data Analysis}

A completely randomized experimental design was applied in both experiments. Resistance $(\mathrm{R})$, reactance $(\mathrm{Xc})$, phase angle (PA), egg weight, and chick data were submitted to analysis of variance (ANOVA) using SAS 9.2 statistical program (SAS, 2009), and means were compared by the t-test at $5 \%$ significance level. Because chick weight was considered in the EBI experiment, EBI experimental data were compared as a function of egg storage time and genetic strain.

\section{RESULTS AND DISCUSSION}

The bioimpedance (EBI and $\mathrm{BBI}$ ) results of both experiments demonstrated that it can be used to obtain quality measurements of eggs and poultry.

An average PA value of $55.17^{\circ}$ was determined in eggs stored for different periods by egg bioimpedance (EBI), clearly showing that the egg can be considered a capacitive body. This result may attributed to egg composition, which includes a calcareous eggshell (Hincke et al., 2012), proteins and peptides in the egg membranes (Makkar et al., 2015), lipids in the yolk (Anderson, 2011), and water and proteins in the albumen (Willems et al., 2014).

Eggs stored for zero and seven days presented different PA and $R$ values (Table 1). Egg PA values were significantly different between storage times $(p<0.05)$, with eggs store for zero days presenting higher PA values. This may be attributed to the fact that eggs lose water (Willems et al., 2014), and the number of blastodermal cells and the rate of apoptosis are reduced (Hamidu et al., 2010; Hamidu et al, 2011) during storage. The higher $\mathrm{R}$ values obtained in eggs stored for seven days is explained by the fact that $R$ is inversely proportional to the body hydration level (Baumgartner et al., 1988; Dou et al., 2011).
Table 1 - Mean resistance $(R)$, reactance $(X c)$, phase angle (PA), and egg weight values of eggs stored for different times.

\begin{tabular}{llll}
\hline & \multicolumn{3}{c}{ Days of storage } \\
\hline Variable & Zero & Seven & CV (\%) \\
\hline Phase angle & $55.29^{\mathrm{a}}$ & $55.04^{\mathrm{b}}$ & 0.65 \\
\hline Resistance & $454.60^{\mathrm{b}}$ & $457.20^{\mathrm{a}}$ & 1.07 \\
\hline Reactance & $647.83^{\mathrm{a}}$ & $647.60^{\mathrm{a}}$ & 0.67 \\
\hline Egg weight $(\mathrm{g})$ & $57^{\mathrm{a}}$ & $56^{\mathrm{a}}$ & 6.04 \\
\hline
\end{tabular}

Different letters in the same row indicate significant differences between values $(\mathrm{p}<0.05)$ by the $t$-test.

Zero $=$ non-stored eggs, evaluated on collection day; Seven = eggs stored for seven days after collection, CV = coefficient of variation.

Reactance and egg weight values were not different between storage days $(P>0.05)$. Such statistically similar reactance values may be justified by the fact that dehydration does not affect eggshell membranes. Egg weight was not influenced by storage time, despite the slight numerical reduction observed in eggs stored for seven days, as previously observed by Gharib (2013).

Broiler breeders' eggs presented higher $\mathrm{R}$ values compared with layer breeders' eggs, which maybe associated with the heavier weight of the eggs laid by broiler breeders (Table 2). When strains are compared, it is likely that the observed differences are also related to differences in yolk to albumen. According to Ho et al. (2011) and Tưmová \& Gous (2012), the broiler breeders' eggs present higher yolk to albumen ratios compared with layer breeders' eggs, because when egg mass increases, albumen mass proportionately increases, whereas yolk mass decreases (Nelson et al., 2010)

Table 2 - Mean resistance $(R)$, reactance $(X c)$, phase angle (PA), and egg weight values of eggs laid by broiler breeders and two layers of two different strains.

\begin{tabular}{lllll}
\hline & \multicolumn{4}{c}{ Strain } \\
\hline Variables & \multicolumn{1}{c}{ BB } & \multicolumn{1}{c}{ RW } & \multicolumn{1}{c}{ RB } & CV (\%) \\
\hline Phase angle & $55.01^{\mathrm{b}}$ & $55.21^{\mathrm{ab}}$ & $55.27^{\mathrm{a}}$ & 0.65 \\
\hline Resistance & $460.85^{\mathrm{a}}$ & $454.45^{\mathrm{b}}$ & $452.45^{\mathrm{b}}$ & 1.07 \\
\hline Reactance & $636.25^{\mathrm{b}}$ & $654.20^{\mathrm{a}}$ & $653.70^{\mathrm{a}}$ & 0.67 \\
\hline Egg weight & $0.59^{\mathrm{a}}$ & $0.55^{\mathrm{b}}$ & $0.56^{\mathrm{b}}$ & 6.04 \\
\hline
\end{tabular}

Different letters in the same row indicate significant differences between values $(p<0.05)$ by the $t$-test.

$\mathrm{BB}=$ broiler breeders; RW = Rhode Island Red $\mathrm{x}$ White Plymouth Rock (RW) layers; RB $=$ Rhode Island Red $x$ Barred Plymouth Rock (RB) layers. CV = coefficient of variation.

An average phase angle value of $41.87^{\circ}$ was by day old chicks. The PA value, near $45^{\circ}$, indicates that chick's body contained showed similar $\mathrm{R}$ and Xc proportions, because a PA value close zero represents a resistive body (basically consisting of fat) and $90^{\circ}$ corresponds to a capacitance body (consisting of fluids). 
Phase angle and $\mathrm{R}$ were significantly different $(p<0.05)$ among strains (Table 3$)$. The PA of chicks from RB layers was significantly higher than of that of broiler breeders' chicks, whereas RW chicks presented intermediate value. These differences may be attributed to body size, because layer chicks are smaller than broiler chicks (Wilson, 1991). Chicks body size is influenced by egg weight, weight loss during incubation, genetic strain (Wilson, 1991; Tůmová \& Gous, 2012), and embryo body mass (Buzala et al., 2015), which is greater in broilers than in layers.

Table 3 - Mean resistance $(R)$, reactance $\left(X_{c}\right)$, phase angle (PA) of the body of day-old chicks derived from broiler breeders and two layers of two different strains.

\begin{tabular}{lcccl}
\hline & \multicolumn{4}{c}{ Strains } \\
\cline { 2 - 5 } Variables & BB & RW & RB & CV (\%) \\
\hline Phase angle & $38.180^{\mathrm{b}}$ & $40.891^{\mathrm{ab}}$ & $46.553^{\mathrm{a}}$ & 0.16 \\
Resistance & $544.25^{\mathrm{b}}$ & $618.50^{\mathrm{ab}}$ & $655.33^{\mathrm{a}}$ & 0.16 \\
\hline Reactance & $527.00^{\mathrm{a}}$ & $543.33^{\mathrm{a}}$ & $574.50^{\mathrm{a}}$ & 0.23 \\
\hline
\end{tabular}

Different letters in the same row indicate significant differences between values $(p<0.05)$ by the $t$-test.

$\mathrm{BB}=$ broiler breeders; RW = Rhode Island Red $x$ White Plymouth Rock (RW) layers; RB $=$ Rhode Island Red $x$ Barred Plymouth Rock (RB) layers. CV = coefficient of variation.

No significant differences between sexes were found for the evaluated parameters (Table 4). Factors such as body positioning, and electrode placement and type may influence the outcomes of BBI measurements (Kushner et al., 1990; Cintra et al., 2010; Marquezet al., 2013). In the present study, changes made in electrode positioning or adaptation to copper connectors to match bird size may have influenced the results. In humans, BBI values are typically different between sexes, because women have a higher body fat content than men; however, there are few such studies on animals (Kushner et al., 1990; Pichard et al. 2000). Stanton et al. (1992) developed prediction equations to determine the lean body mass in cats, but did not specify $R$ and $X_{C}$ values. In addition, factors such as body positioning, body temperature, hydration degree, serum electrolytes, age, and health status also influence the values measured by BBI (Kushner et al. 1990, Mialich et al., 2014).

Table 4 - Mean resistance $(R)$, reactance $(X c)$, and phase angle (PA) values of day-old male and female chicks.

\begin{tabular}{lccc}
\hline Sex & $\mathrm{R}$ & $\mathrm{Xc}$ & $\mathrm{PA}$ \\
\hline Male & 612.83 & 567.89 & 42.49 \\
Female & 599.22 & 528.67 & 41.26 \\
CV $(\%)$ & 16.43 & 23.85 & 16.58 \\
\hline
\end{tabular}

Values are not significantly different $(p>0.05)$ by the $t$-test.

The PA and Xc values obtained in eggs and chicks were significantly different between layers and broiler breeders chicks, as shown in Tables 2 and 3. Higher values in PA and Xc indicate better chick quality and cellular integrity (Gupta et al., 2004). Those values suggest layer breeder eggs present better than broiler breeder eggs, and that layer chicks may be more resistant to heat stress because of their better endothermic response relative to broiler chicks (Andrewartha et al., 2011).

\section{CONCLUSIONS}

The results of the study indicate that $\mathrm{BBI}$ and $\mathrm{EBI}$ may be used as non-invasive methods to measure the quality of eggs and day-old chicks. However, further studies should be conducted to validate these techniques.

The use of body bioimpedance (BBI) identified differences in the resistance and phase angle values among chicken strains, but not between sexes.

The egg bioimpedance (EBI) method identified egg quality differences as a function of egg storage time. Eggs stored for seven days presented higher resistance and lower phase angle than those evaluated immediately after collection. Eggs from different chicken strains presented different resistance and reactance values. This method allows determining the quality of eggs and chicks as well as differentiating laying from broiler strains.

\section{ACKNOWLEDGEMENTS}

The authors thank Fapergs/Capes (Fundação de Amparo à Pesquisa do Estado do Rio Grande do Sul/ Coordenação de Aperfeiçoamento de Pessoal de Nível Superior) for the scholarships provided.

\section{REFERENCES}

Anderson KE. Comparison of fatty acid, cholesterol, and vitamin A and E composition in eggs from hens housed in conventional cage and range production facilities. Poultry Science 2011;90:1600-1608.

Andrewartha SJ, Tazawa H, Burggren WW. Embryonic control of heart rate: examining developmental patterns and temperature and oxygenation influences using embryonic avian models. Respiratory Physiology and Neurobiology 2011;178:84-96.

Baumgartner RN, Chumlea WC, Roche AF. Bioelectric impedance for body composition.American Journal of Clinical Nutrition 1988;48(1):16-23.

Brake J, Walsh TJ, Benton CE, Petitte JN, Meijerhof R, Penalva G. Egg handling and storage. Poultry Science 1997;76:144-151.

Buzala M, Janicki B, Czarnecki R. Consequences of different growth rates in broiler breeder and layer hens on embryogenesis, metabolism and metabolic rate: A review. Poultry Science 2015;94:728-733. 
Chumlea WC, Guo SS. Bioelectrical impedance and body composition: present status and future directions. Nutrition Reviews 1994;52(4):123131.

Cintra TCF, Canola JC, Borges NC, Carciofi AC, Vasconcelos RS, Zanatta R. Influência de diferentes tipos de eletrodos sobre os valores da bioimpedância corporal e na estimativa de massa magra $(\mathrm{mm})$ em gatos adultos. Ciência Animal Brasileira 2010;11(1):149-155.

Collins CT, Reid J, Makrides M, Lingwood BE, Mcphee AJ, Morris SA, et al. Prediction of body water compartments in preterm infants by bioelectrical impedance spectroscopy. European Journal of Clinical Nutrition 2013;67:S47-S53.

Dittmar M, Reber H, Kahaly G J. Metabolism bioimpedance phase angle indicates catabolism in Type 2 diabetes. Diabetic Medicine 2015;32:1177-1185

Dou Y, Liu L, Cheng X, Cao L, Zuo L. Comparison of bioimpedance methods for estimating total body water and intracellular water changes during hemodialysis. Nephrology Dial Transplant 2011;26(10):3319-3324.

Dymond J, Vinyard B, Nicholson AD, French NA, Bakst MR. Short periods of incubation during egg storage increase hatchability and chick quality in long-stored broiler eggs. Poultry Science 2013;92:2977-2987.

Gharib HB. Effect of pre-storage heating of broiler breeder eggs, stored for long periods, on hatchability and chick quality. Egyptian Journal of Animal Production 2013;50(3):174-184.

Gupta D, Lammersfeld CA, Burrows JL, Dahlk SL, Vashi PG, Grutsch JF. Bioelectrical impedance phase angle in clinical practice: implications for prognosis in advanced colorectal cancer. American Journal of Clinical Nutrition 2004;80(6):134-138

Hamidu JA, Rieger A, Fasenko GM, Barreda DR. Dissociation of chicken blastoderm for examination of apoptosis and necrosis by flow cytometry. Poultry Science 2010;89:901-909.

Hamidu JA, Uddim Z, Li M, Fasenko GM, Guam LL, Barreda, DR. Broiler egg storage induces cell death and influences embryo quality. Poultry Science 2011;90:1749-1757.

Harrison AP, Elbrønd VS, Riis-Olesen K, Bartels EM. Multi-frequency bioimpedance in equine muscle assessment. Physiological Measurement 2015;36:453-464.

Hincke MT, Nys Y, Gautron J, Mann K, Rodriguez-Navarro AB, McKee MD. The eggshell: structure, composition and mineralization. Frontiers in Bioscience 2012;17: 1266-1280.

Ho DH, Reed WL, Burggren WW. Egg yolk environment differentially influences physiological and morphological development of broiler and layer chicken embryos. Journal of Experimental Biology 2011;214:619628.

Karelis AD, Aubertin-Leheudre M, Duval C. Validation of a portable bioelectrical impedance analyzer for the assessment of body composition. Applied Physiological Nutrition and Metabolism 2013;38:27-32.

Kushner RF, Kunigk A, Alspaugh M, Andronis PT, Leitch CA, Scholler DA. Validation of bioelectrical impedance analysis as a measurement of change in body composition in obesity. The American Journal of Clinical Nutrition 1990;52:219-223.

Kyle UG, Genton L, Pichard C. Low phase angle determined by bioelectrical impedance analysis is associated with malnutrition and nutritional risk at hospital admission. Clinical Nutritrition 2013;32(2):294-299.

Llames L, Baldomero V, Iglesias ML, Rodota YLP. Valores del ángulo de fase por bioimpedancia eléctrica; estado nutricional y valor pronóstico. Nutrición Hospitalaria 2013;28(2):286-295.

Lukaski HC. Evolution of bioimpedance: a circuitous journey from estimation of physiological function to assessment of body composition and a return to clinical research. European Journal of Clinical Nutrition 2013;67(Suppl 1):S2-S9, 2013.

Makkar S, Liyanage R, Kannan L, Packialakshmi B, Lay Jr JO, Rath NC. Chicken egg shell membrane associated proteins and peptides. Journal of Agricultural and Food Chemistry 2015;63:9888-9898.

Marquez JC, Seoane F, Lindecrantz K. Textrode functional straps for bioimpedance measurements experimental results for body composition analysis. European Journal of Clinical Nutrition 2013;67:S22-S27.

Mialich MS, Sicchieri JMF, Jordao Jr AA. Analysis of body composition: a critical review of the use of bioelectrical impedance analysis. International Journal of Clinical Nutrition 2014;2(1):1-10

Nelson TC, Groth KD, Sotherland PR. Maternal investment and nutrient use affect phenotype of American alligator and domestic chicken hatchlings. Comparative Biochemistry and Physiology 2010;157:19-27.

Omana DA, Liang Y, Kav NNV, Wu J. Proteomic analysis of egg white proteins during storage. Proteomics 2011,11:144-153.

Pichard C, Kyle UG, Bracco D, Slosman DO, Morabia A, Achutz Y. Reference values of fat-free and fat masses by bioelectrical impedance analysis in healthy subjects. Nutrition 2000;16:245-254.

SAS. Statistical analysis system. User'guide. Stat version. Cary; 2009.

Stanton CA, Hamar DW, Johnson DE, Fettman MJ. Bioelectrical impedance and zoometry for body composition analysis in domestic cats. American Journal of Veterinary Research 1992;53(2):251-257.

Tůmová E, Gous RM. Interaction between oviposition time, age, and environmental temperature and egg quality traits in laying hens and broiler breeders. Czech Journal of Animal Science 2012;57(12):541549.

Willems E, Decuypere E, Buyse J, Everaert N. Importance of albumen during embryonic development in avian species, with emphasis on domestic chicken. World's Poultry Science Journal 2014;70:503-517.

Wilson HR. Interrelationships of egg size, chick size, posthatching growth and hatchability. World's Poultry Science Journal 1991;47(1):5-20.

Yaguiyan-Colliard L, Daumas C, Bousbiat S, Jaffrin M, Cardot P, Grandjean $D$, et al. Indirect prediction of total body water content in healthy adult Beagles by single frequency bioelectrical impedance analysis. American Journal of Veterinary Research 2015;76(6):547-553. 
